and the fact that the contents of each pollen grain have to pass through the coats, both of the pollen tube and of the embryonic sack." (I extract these Iatter addenda from Mr. Darwin's letter.)

I do not much complain of having been sent on a false quest by ambiguous language, for I know how conscientious $\mathrm{Mr}$. Darwin is in all he writes, how difficult it is to put thoughts into accurate speech, and, again, how words have conveyed false impressions on the simplest matters from the earliest times. Nay, even in that idyllic scene which Mr. Darwin has sketched of the first invention of language, awkward blunders must of necessity have often occurred. I refer to the passage in which he supposes some unusually wise, ape-like animal to have first thought of imitating the growl of a beast of prey so as to indicate to his fellow monkeys the nature of expected danger. For my part, I feel as if $I$ had just been assisting at such a scene. As if, having heard my trusted leader utter a cry, not particularly well articulated, but to my ears more like that of a hyena than any other animal, and seeing none of my companions stir a step, I had, like a loyal member of the flock, dashed down a path of which I had happily caught sight, into the plain below, followed by the approving nods and kindly grunts of my wise and most-respected chief. And I now feel, after returning from my hard expedition, full of information that the suspected danger was a mistake, for there was no sign of a hyena anywhere in the neighbourhood. I am given to understand for the first time that my leader's cry had no reference to a hyena down in the plain, but to a leopard somewhere up in the trees; his throat had been a little out of order - that was all. Well, my labour has not been in vain; it is something to have established the fact that there are no hyenas in the plain, and I think I see my way to a good position for a look out for leopards among the branches of the trees. In the meantime, Vive Pangenesis.

FRANCIS GaLTON

\section{The Hylobates Ape and Mankind}

THE readers of Mr. Mivart's communication in NATURE for April 20, on the affinity of the Hylobates genus of ape to the human species, may be interested to learn that the fact was well known to the author of the Ramayana, the earliest Sanscrit epic, probably contemporaneous with the Iliad. In this poem the demigod Rama subdues the demon Ravana, and regains his ravished bride Sita by the assistance of a host of apes, which may be identified with Hylobates Fioolook. The human characteristics of these semi-apes, their gentleness, affection, good humour, sagacity, self-importance, impressionability, and proneness to melancholy, are portrayed with the most vivid strokes, and evidently from careful observation. See Miss Frederika Richardson's charming volume, "The Iliad of the East," a selection of legends drawn from the Ramayana. (Macmillan and Co., i87o.) April 27

R. G.

\section{Tables of Prime Numbers}

WHEN a number is given, and it is required, without the aid of tables, to find its factors, there is not, I believe, any other method known except the simple but laborious one of dividing it by every odd number until one is found that measures it, and if the number should be prine, this can only be proved by showing that it is not divisible by any odd number less than its square root. Thus to prove that 6966007 is prime, it would be necessary to divide it by every odd number less than 2639 , and even if a table of primes less than 2639 were at hand, about 380 divisions would be requisite.

On the other hand, there are few tables which are more easily constructed than tables of divisors, and it is the extreme facility of a systematic tabulation compared to the labour of isolated determinations, which has led to the construction of such elaborate tables on the subject as have been produced.

The principal tables are Chernac's, which give the factors of numbers from unity to a million; Burckhardt's, which extend as far as three millions, and Dase's, which form a contintation of Burckhardt's, and extend to ten millions.

The mode of formation of these tables was extremely simple, By successive additions, the multiples of $3,5,7$, I I , I3, 17 . . were formed up to the limit to which the table wasintended to extend; this gave all the numbers having these numbers for factors, and the primes were recognised irom the fact of their not occurring as multiples of another prime less than themselves.

Practically the work was rendered even simpler by mechanical means; thus, forms were printed containing, say, a thousand squares, and in these were written consecutive thousands of odd numbers in order; one number in each square, room being left for its divisors, if any, in the square. A pair of compasses was then taken and opened a distance corresponding to the prime whose multiples were to be obtained ; for example, in marking the multiples of seven, the compasses were opened the width of seven squares, and then "stepped" along the lines starting from 7 , thereby marking the numbers $7,21,35 . \cdots$ and the number 7 was written in each of the squares in which a leg of the com. passes fell. When the factor was large it was more convenient to form a separate table of its multiples, and enter it in the square corresponding to the latter. Many simplifications were introduced in the details of the construction ; for instance, Burckhardt had a copper plate engraved with $77(=7 \times 1 \mathrm{r})$ squares one way and 80 the other; by this arrangement the multiples 7 and II, which were of the most frequent occurrence (for all multiples of 2, 3, and 5 were rejected from the tables), occupied the same place on each sheet, and he was thus enabled to engrave the numbers 7 and I I on the plate, so that these numbers were printed in all the squares containing the numbers they measured.

Dase, who originally applied himself to the construction of the tables at the suggestion of Gauss, left behind him in manuscript at the time of his death, in 1862 , the seventh and part of the eighth million complete, besides a considerable portion of the ninth and tenth millions. The seventh, eighth, and ninth millions were completed by Dr. Rosenberg, and published by a committee at Hamburgh. In the preface to the ninth million (I865), which is the last I have seen, it is stated that the tenth million, which was nearly ready, was the last the committee intended to publish.

My object in writing this letter is not orily to call attention to a most valuable series of tables, which seem to have scarcely excited so much interest as they deserve, but also to ask if any of your readers can inform me if the work is being continued, or if there is any chance of its continuation. It is not often that tables are so indispensable as in the present case, or that a want so pressing can be supplied with such comparative ease ; and the cessation of the tables would be a real calamity. The tenth million has, I presume, been published.

At the British Association Meeting at Dundee in I867, a list of 5,500 large prime numbers was communicated to Section A by Mr. Barrett Daris. A short discussion took place on the "reading" of the paper, in the course of which it was stated that Mr. Davis's table was unaccompanied by any explanation of how the numbers had been obtained, or on what grounds they were asserted to be prime; it was also asserted that Mr. Davis wished to keep his method secret.

Perhaps some reader of NATURE can say whether Mr. Davis's numbers have been printed. If they exceed Dase's limait, their publication (if they have not yet been published) is very desirable; and even supposing they are given in Dase's tables, it would be valuable to know how far the latter have been verified by them. The statement about Mr. Davis's method being secret was probably founded on some mistake, and no doubt Mr. Davis would not object to explain it.

Trinity College, Cambridge, April 29

\section{Units of Force and Energy}

THE best root for the name of a unit of force is $\delta v^{t} \nu a \mu t s$. There is, therefore, no ground for Mr. Muir's complaint (NATURE, vol. iii. p. 426), and I now venture to propose that the name dyne be given to that force which, acting on a gramme for a second, generates a velocity of a metre per second. A thousand dynes to make one kilodyne, and a million dynes one megadyne.

Borrowing a hint from Mr. Muir, I would point out that the kilodyne may also be defined as the force which, acting on a kilogranme for a second, generates the velocity of a metre per second, or, as the force which, acting on a gramme for a second, generates a velocity of a kilcmintre per second.

The kinit, or pound-fcot-second unit of force, is about $138 \frac{1}{4}$ dynes. Very roughly expressed in terrestrial gravitation measure, the kinit is the gravitating force of half an ounce, the dyne of about $1 \frac{1}{2}$ grains, the kilod) ne of about $\frac{1}{4}$ of a pound, and the megadyne of $2 \mathrm{cwt}$, the approximation being much closer in this last case than in the others, so that within one part in 4 co we have Io megadynes $=$ the force of terrestrial gravity on a ton.

I have often felt the want of a name for an absolute unit of energy, or, what amounts to the same thing, an absolute unit of 